\title{
Glassy Carbon Electrodes Deliver Unpredictable Reduction Potentials for Platinum(IV) Antitumor Prodrugs
}

\author{
Meghan C. McCormick, ${ }^{a}$ Franklin A. Schultz, ${ }^{b}$ and Mu-Hyun Baik ${ }^{\mathrm{c}, \mathrm{d}, *}$
}

${ }^{a}$ Department of Chemistry, Indiana University, 800 East Kirkwood Avenue, Bloomington, Indiana 47405

${ }^{\mathrm{b}}$ Department of Chemistry, Indiana University-Purdue University Indianapolis, 402 N. Blackford St., Indianapolis, IN 46202

${ }^{c}$ Department of Chemistry, Korea Advanced Institute of Science and Technology (KAIST), Daejeon 339-701, South Korea.

${ }^{\mathrm{d}}$ Center for Catalytic Hydrocarbon Fuctionalization, Institute for Basic Science (IBS), Daejeon 339-701, South Korea.

This paper is dedicated to Professor Malcolm Chisholm on the occasion of his $70^{\text {th }}$ birthday and in celebration of his many contributions to organometallic chemistry.

Email: mbaik2805@kaist.ac.kr

KEYWORDS. Electrochemistry, Non-Nernstian Redox Behavior, Electrode, Pt(IV) prodrugs, Cisplatin

ABSTRACT: Reductive activation of six-coordinate Pt(IV) complexes to afford square-planar Pt(II) complexes has exhibited surprisingly divergent and unpredictable cathodic peak potentials during cyclic voltammetry (CV) measurements under widely employed experimental conditions. A systematic, detailed investigation reveals that glassy carbon (GC) electrodes are responsible for this erratic behavior. More reproducible cyclic voltammograms are obtained with platinum metal electrodes, which display cathodic responses at much more positive potentials. The unreliable and negatively shifted peak potentials observed at GC are attributed to a non-uniform oxide layer that is formed on the electrode surface causing slow electron transfer. A simple procedure of repetitive scanning to reducing potentials is found to be effective for cleaning and activating the GC surface, such that it exhibits the more consistent and accurate peak potential responses seen with a Pt electrode. 


\section{Introduction}

Cyclic voltammetry (CV) often is the method of choice for investigating the electrochemical properties of inorganic complexes. As such, it is important to establish that the measured voltammetric parameters correlate accurately with the chemical properties of interest. A common practice for obtaining the standard redox potential, $\mathrm{E}^{\circ}$, is to average the cathodic and anodic peak potentials, $\mathrm{E}_{\mathrm{pc}}$ and $\mathrm{E}_{\mathrm{pa}}$. However, if the electrode reaction is irreversible by virtue of either slow electron transfer kinetics or a coupled chemical reaction, such as electrochemically triggered bond cleavage, only the cathodic peak potential may be observed during the course of a reduction. ${ }^{1}$ In these irreversible cases, the common protocol of averaging $\mathrm{E}_{\mathrm{pc}}$ and $\mathrm{E}_{\mathrm{pa}}$ cannot be applied. Moreover, the irreversible peak potential may shift to either positive or negative values with its position and shape varying as a function of scan rate, making it difficult to obtain an accurate estimate of the true $\mathrm{E}^{\circ}$. Another serious and often unappreciated problem is that redox reactions become non-Nernstian when chemical events like ligand loss disturb the equilibrium connecting the oxidized and reduced forms. Typically, the concentration of the free ligand in the electrolyte solution is negligibly small, which makes it impossible to establish a chemical equilibrium between the reactant and product states. Because the Nernst equation assumes that oxidants and reductants are in thermodynamically well-defined equilibrium, chemically irreversible redox reactions are nonNernstian by default, adding significantly to the difficulty of interpreting the electrochemical responses of these complicated, but relatively common processes.

Recently, ${ }^{2}$ we studied the electrochemical reduction of several six-coordinate $\mathrm{Pt}(\mathrm{IV})$ complexes that are representative examples of third generation antitumor prodrugs. ${ }^{3-23}$ These compounds undergo two-electron reduction accompanied by loss of two axial ligands to afford a square-planar Pt(II) complex (Scheme 1). The resulting voltammetric responses are irreversible. However, by analyzing scan rate-dependent changes in the position and shape of the Faradaic response using a protocol introduced by Jean-Michel Savéant and others ${ }^{24-35}$ we have been able to determine the (stepwise) mechanism of this two-electron process and to extract the standard potential, $\mathrm{E}_{1, \mathrm{~s}}{ }^{\mathrm{o}}$, of the initial one-electron addition to $\mathrm{Pt}(\mathrm{IV})$. 


\section{Scheme 1}

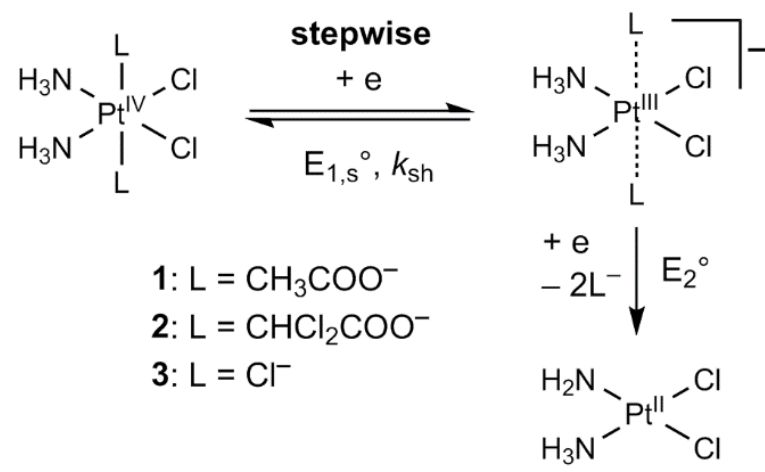

Investigations seeking to establish relationships between structure and activity of these clinically important compounds need to be based on an accurate and reliable determination of a relevant fundamental parameter, in this case the standard reduction potential $\mathrm{E}^{\circ}$. Because of the irreversibility of the electrode reaction, many researchers have chosen to use the cathodic peak potential, $\mathrm{E}_{\mathrm{pc}}$, as a substitute for $\mathrm{E}^{\circ}$ in evaluating the efficacy of $\mathrm{Pt}(\mathrm{IV})$ prodrugs. ${ }^{6,15,16,18-20,23} \mathrm{E}_{\mathrm{pc}}$ is a valid approximation of $\mathrm{E}^{\circ}$ only in the case of nearly ideal, reversible redox reactions, where the separation between $\mathrm{E}_{\mathrm{pc}}$ and $\mathrm{E}_{\mathrm{pa}}$ is ca. $60 / \mathrm{n} \mathrm{mV}$ and $\mathrm{E}_{\mathrm{pc}}$ is more negative than $\mathrm{E}^{\circ}$ by only ca. 30/n mV. ${ }^{1}$ In assessing the relative ease of reduction of various $\mathrm{Pt}(\mathrm{IV})$ prodrugs, researchers have reported $\mathrm{E}_{\mathrm{pc}}$ values measured under comparable, yet arbitrarily established, experimental conditions. The underlying assumption is that potential differences between $\mathrm{E}_{\mathrm{pc}}$ and $\mathrm{E}^{\circ}$ are identical in all circumstances and cancel to generate a qualitatively meaningful correlation. However, the complicated mechanistic and thermodynamic issues discussed above raise serious concerns about the validity of such a simplified approximation, as highlighted in our recent study. ${ }^{2}$ During the course of our work we found that linear sweep and cyclic voltammograms of selected Pt(IV) prodrugs showed irreproducible peak potentials that varied greatly with experimental conditions and produced estimates of $\mathrm{E}^{\circ}$ that were grossly inconsistent with quantum chemically calculated values. Subsequently, we have identified glassy carbon (GC) electrodes to be the source of these inconsistencies and have examined the voltammetric response of $\mathrm{Pt}(\mathrm{IV})$ systems in greater detail at $\mathrm{GC}$ and $\mathrm{Pt}$ electrodes to better understand the extent and nature of the artifactual shifts in peak potential. The goal of this work is to identify the source of the erratic behavior and to provide a basis for interpreting previous work obtained 
at GC electrodes in a conceptually more satisfying manner. In addition, we report a simple experimental procedure that allows more consistent and reliable data to be obtained at glassy carbon electrodes.

\section{Experimental}

\subsection{Synthesis of Complexes}

Platinum prodrugs 1-3 were generously provided by Professor Stephen J. Lippard (Massachusetts Institute of Technology, Cambridge, MA). The general procedures for the synthesis of these prodrugs have been reported previously elsewhere. ${ }^{13,20}$

\subsection{Electrochemistry}

Cyclic voltammetry experiments of all Pt(IV) prodrugs were conducted in a three-electrode cell and recorded at room temperature with an EG\&G PAR 273A or a $\mathrm{CH}$ Instruments 620E potentiostat. The working electrode was a platinum disk (Bioanalytical Systems, area $=0.02 \mathrm{~cm}^{2}$ ) or a glassy carbon disk (Bioanalytical Systems, area $=0.07 \mathrm{~cm}^{2}$ ), the reference electrode was $\mathrm{Ag} / \mathrm{AgCl}$ (Bioanalytical Systems, satd. $\mathrm{NaCl}$ ) and the counter electrode was a platinum wire. The potential of the $\mathrm{Ag} / \mathrm{AgCl}$ electrode is $+0.197 \mathrm{~V}$ vs. SHE. Pt(IV) complexes were dissolved in water to prepare $1 \mathrm{mM}$ solutions with $0.1 \mathrm{M}$ sodium acetate (for 1) or potassium chloride (for $\mathbf{2}$ and $\mathbf{3}$ ) as the supporting electrolyte. Solutions were degassed with Ar for 5-10 min before experimentation, and each voltammogram was collected under a blanket of Ar. The Pt and GC electrodes were polished for at least 2 minutes between trials with $0.05-\mu \mathrm{m} \gamma$-alumina (Buehler) slurry on a polishing cloth (Buehler Microfiber), rinsed clean with DI water and dried with a fiberless cleaning cloth. In cases where the electrode was pre-cleaned or pre-activated by a multiple-scan experiment the electrode was not polished before each scan; rather, the potentiostat was switched off and the solution was stirred under Ar. Scan rates ranging from 0.02 to $1.5 \mathrm{~V} \mathrm{~s}^{-1}$ were used. Peak potentials were either located by fitting a Lorentzian to $\sim 20$ data points close to the maximum current or obtained from the $\mathrm{CHI} 620 \mathrm{E}$ software package (CH Instruments). 


\section{Results and discussion}

Table 1 summarizes the cathodic peak potential, $\mathrm{E}_{\mathrm{pc}}$, associated with the two-electron reduction of $\mathbf{1 - 3}$ determined by us and other investigators under various experimental conditions. Compared to values reported earlier using a glassy carbon electrode, potentials obtained with a Pt electrode are much more positive. The differences range from 260 to $630 \mathrm{mV}$. Namely, the literature results recorded at GC electrodes in $\mathrm{KCl}$ electrolyte are found to be shifted by $534 \mathrm{mV}$ for $\mathbf{1}$ (entry 8), $263 \mathrm{mV}$ for $\mathbf{2}$ (entry 13), and $630 \mathrm{mV}$ for $\mathbf{3}$ (entry 16) relative to those recorded at Pt. Moreover, the range of $\mathrm{E}_{\mathrm{pc}}$ values reported at $\mathrm{GC}$ for a given compound under comparable experimental conditions is quite large (ca. $120-240 \mathrm{mV}$ ) compared to that at $\mathrm{Pt}$ (ca. $10 \mathrm{mV}$ ). Although it is not unexpected that peak potentials may change as different electrode materials are employed, the magnitude of the variance is surprisingly large and represents an inconsistency that has not been satisfactorily explained to date.

To better understand these discrepancies, we conducted experiments under conditions identical to those reported in the literature and found that $\mathrm{E}_{\mathrm{pc}}$ for compound $\mathbf{1}$ in $\mathrm{KCl}$ occurred at a more negative value than at $\mathrm{Pt}$ $(-0.450 \mathrm{~V}$, entry 3$)$. Upon changing the electrolyte to phosphate buffered saline solution to better mimic physiological conditions, the peak potential was observed at $-0.511 \mathrm{~V}$ (entry 4), which is closer to literature values, but divergent from results at Pt. Because it was unclear if the change in electrolyte (and specifically the presence of phosphate salts) caused the negative shift, removal of the phosphate salts to give a $\mathrm{NaCl} / \mathrm{KCl}$ electrolyte mixture produced only a slightly more positive $\mathrm{E}_{\mathrm{pc}}$ of $-0.447 \mathrm{~V}$ (entry 5). However, the latter condition exhibited a more negative value $(-0.555 \mathrm{~V}$, entry 6$)$ after a $20 \mathrm{~h}$ period in a separate run. The difference between the last two potentials, obtained using the same experimental setup and conditions, is worrisome, because changes in peak potential of over $100 \mathrm{mV}$ without an obvious reason cast doubt on the reliability of the measurements.

\section{Table 1.}

Cathodic peak potentials at $0.1 \mathrm{~V} \mathrm{~s}^{-1}$ from this and previously published work for compounds $\mathbf{1}-\mathbf{3}$ at platinum and glassy carbon working electrodes. $\mathrm{E}_{\mathrm{pc}}$ values from this work represent average values obtained from at least 3 trials.

\begin{tabular}{llllll}
\hline Entry & Compound & Reference & Electrode & Electrolyte & $\mathrm{E}_{\mathrm{pc}}(\mathrm{V})^{d}$ \\
\hline
\end{tabular}




\begin{tabular}{cccccc}
\hline 1 & $\mathbf{1}$ & $a$ & $\mathrm{Pt}$ & $\mathrm{KCl}$ & -0.158 \\
2 & $\mathbf{1}$ & $a$ & $\mathrm{Pt}$ & $\mathrm{NaOAc}$ & -0.155 \\
3 & $\mathbf{1}$ & $a$ & $\mathrm{GC}$ & $\mathrm{KCl}$ & -0.450 \\
4 & $\mathbf{1}$ & $a$ & $\mathrm{GC}$ & $\mathrm{PBS}^{b}$ & -0.511 \\
5 & $\mathbf{1}$ & $a$ & $\mathrm{GC}$ & $\mathrm{KCl}+\mathrm{NaCl}$ & -0.447 \\
6 & $\mathbf{1}$ & $a$ & $\mathrm{GC}$ & $\mathrm{KCl}+\mathrm{NaCl}$ & -0.555 \\
7 & $\mathbf{1}$ & 21 & $\mathrm{GC}$ & $\mathrm{KCl}$ & -0.635 \\
8 & $\mathbf{1}$ & 13 & $\mathrm{GC}$ & $c$ & -0.689 \\
9 & $\mathbf{1}$ & 22 & $\mathrm{GC}$ & $\mathrm{KCl}$ & -0.565 \\
10 & $\mathbf{2}$ & $a$ & $\mathrm{Pt}$ & $\mathrm{KCl}$ & 0.083 \\
11 & $\mathbf{2}$ & $a$ & $\mathrm{Pt}$ & $\mathrm{NaOAc}$ & 0.090 \\
12 & $\mathbf{2}$ & $a$ & $\mathrm{GC}$ & $\mathrm{KCl}$ & 0.091 \\
13 & $\mathbf{2}$ & 4 & $\mathrm{GC}$ & $\mathrm{PBS} / \mathrm{KCl}$ & -0.173 \\
14 & $\mathbf{3}$ & $a$ & $\mathrm{Pt}$ & $\mathrm{KCl}$ & 0.370 \\
15 & $\mathbf{3}$ & $a$ & $\mathrm{GC}$ & $\mathrm{KCl}$ & -0.122 \\
16 & $\mathbf{3}$ & 21 & $\mathrm{GC}$ & $\mathrm{KCl}$ & -0.260 \\
17 & $\mathbf{3}$ & 22 & $\mathrm{GC}$ & $\mathrm{KCl}$ & -0.204 \\
\hline$a=$ This work, $b=$ phosphate buffered saline solution, $c=\mathrm{Electrolyte}$ was not \\
specified in reference $13, d=\mathrm{V}$ vs. Ag/AgCl & &
\end{tabular}

Similar to results obtained for compound 1 significant differences in $\mathrm{E}_{\mathrm{pc}}$ values were found for compound 3 with values obtained at Pt being more positive than those reported under identical experimental conditions using a GC electrode. For example, we observed a peak potential at $-0.122 \mathrm{~V}$ (entry 15 ), which although relatively close to values of -0.260 and $-0.204 \mathrm{~V}$ reported previously, ${ }^{21,22}$ is nearly $500 \mathrm{mV}$ more negative than the platinum electrode result of $+0.370 \mathrm{~V}$ (entry 14). The $\mathrm{E}_{\mathrm{pc}}$ value for $\mathbf{2}$ measured in this work with a GC electrode (entry 12) is equal within $\pm 10 \mathrm{mV}$ to the value obtained at Pt. This agreement is deceiving, however, because $\mathrm{E}_{\mathrm{pc}}$ values from individual voltammetric trials at an identical scan rate deviate by as much as $47 \mathrm{mV}$ from the average. The lack of precision of peak potential measurements at GC electrodes, which is apparent from the results plotted in Figure 1, is discussed further below.

Given the puzzling and erratic behavior of measurements at GC electrodes, we questioned whether peak potentials observed for compounds $\mathbf{1}-\mathbf{3}$ varied as a function of scan rate in a manner consistent with theoretical expectations. For a standard irreversible system, $E_{\mathrm{pc}}$ should depend linearly on log (v), where $v$ is the scan rate. ${ }^{1}$ Figure 1 compares this dependence for both glassy carbon and platinum electrodes. It is evident that a general linear trend is followed in all cases, but the error bars at each point illustrate how large the deviations are for GC 
electrode measurements. Specifically, the $\mathrm{E}_{\mathrm{pc}}$ of $\mathbf{1}$ deviates by as much as $\pm 33 \mathrm{mV}$ at a scan rate of $0.1 \mathrm{~V} \mathrm{~s}^{-1}$ when a GC electrode is used (Figure 1b), whereas $E_{\mathrm{pc}}$ values measured for $\mathbf{1}$ at Pt (Figure 1a) display a maximum deviation from the average of $\pm 11 \mathrm{mV}$ (at $1 \mathrm{~V} \mathrm{~s}^{-1}$ ). For compound $3, \mathrm{E}_{\mathrm{pc}}$ values at GC vary by as much as $\pm 26 \mathrm{mV}$ at a scan rate of $0.1 \mathrm{~V} \mathrm{~s}^{-1}$ (Figure 1f) in contrast to a maximum deviation (at $0.5 \mathrm{~V} \mathrm{~s}^{-1}$ ) of $\pm 7 \mathrm{mV}$ for Pt (Figure 1e). Surprisingly, a large negative shift of $E_{p c}$ is not seen for 2 when comparing values obtained at Pt and GC (Figure 1c, 1d). Nevertheless, the reliability of the linear $E_{p c}$ versus $\log (v)$ fit is questionable considering the substantial deviations observed at GC for most scan rates. The most notable uncertainty occurs at $0.05 \mathrm{~V} \mathrm{~s}^{-1}$, where the standard deviation is $47 \mathrm{mV}$ and the range of values is $91 \mathrm{mV}$. Apart from the deceptively linear trend in $\mathrm{E}_{\mathrm{pc}}$ versus $\log (v)$ plots produced by using average values, it is crucial to note that the imprecise responses at GC electrodes are offset significantly in the negative direction relative to Pt electrode measurements. The differences are as large as $300 \mathrm{mV}$ in the case of compound $\mathbf{1}$ and $430 \mathrm{mV}$ in the case of compound $\mathbf{3}$.

(a)

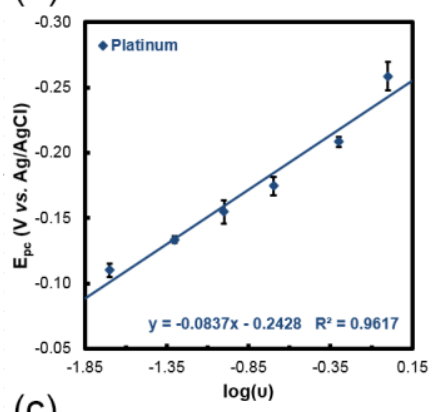

(c)

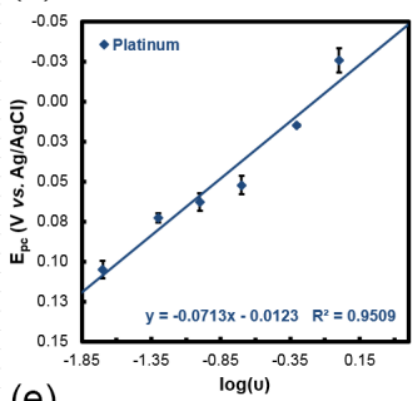

(e)

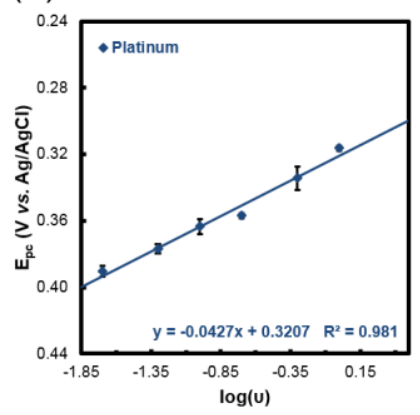

(b)

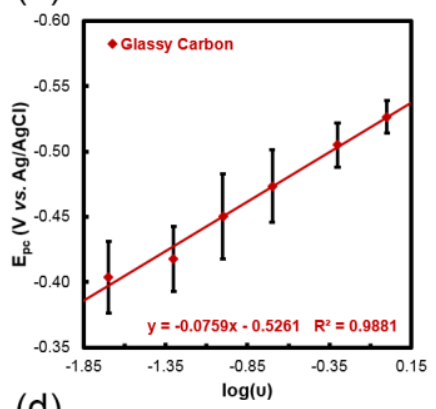

(d)

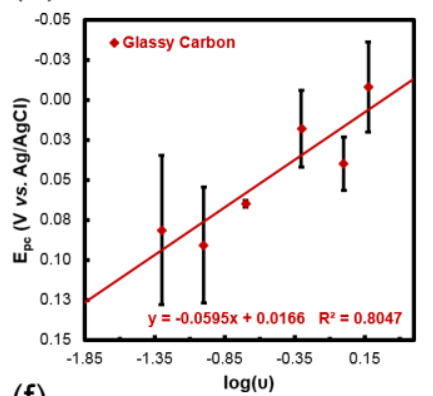

(f)

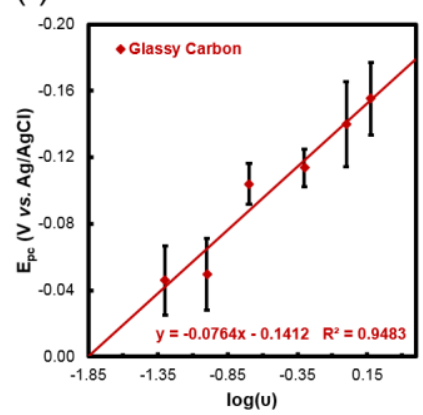


Fig. 1. Plots of $\mathrm{E}_{\mathrm{pc}}(\mathrm{V}$ vs. $\mathrm{Ag} / \mathrm{AgCl})$ as a function of $\log (\mathrm{v})$ illustrating the inconsistencies and unpredictability in using a glassy carbon electrode (b, d and f) compared to a platinum electrode (a, c and e) for compounds 1-3 (from top to bottom). At least three individual trials were conducted at each scan rate leading to the average $\mathrm{E}_{\mathrm{pc}}$ values shown.

One explanation for the observations described above is based on the interaction of the Pt(IV) complex with the poorly defined surface of the glassy carbon electrode during electron transfer, which results in the overall kinetics becoming highly dependent on the specific constitution of the GC surface -- specifically, the oxide contaminants on carbon that change both in composition and coverage with time and treatment. ${ }^{36-43}$ Generally, these inhomogeneously distributed oxides and other contaminants are introduced most extensively through conventional forms of electrode polishing (i.e., use of alumina slurries), which can imbed contaminants in the microstructure of the carbon surface or create an undefined distribution and thickness of surface oxides that can only be removed through more rigorous forms of pre-treatment, e.g., heat and laser treatments. ${ }^{36,37,40,41}$ Even complexes that undergo a purely outer-sphere redox reaction will be affected by a uniform surface film on the electrode; specifically, the electron-transfer rate is slowed by the need for the electron to tunnel through the film between the reactant and the electrode surface. ${ }^{44}$ If surface-bound oxides are the main contributors to the observed inconsistencies, we speculate that the GC surface may be activated by repetitive sweeping to highly reducing potentials, which either reduces or reconstitutes the surface oxides. If so, a more consistent carbon surface with a significantly reduced amount of oxide may be prepared.

To test this hypothesis we carried out the multi-scan CV experiment illustrated in Figure 2, which shows the overlay of representative voltammograms obtained for reduction of compound $\mathbf{3}$ at GC and Pt electrodes. To clarify, the multiple-scan CV experiments allowed scanning over a specified potential window with no delay in between each scan. 

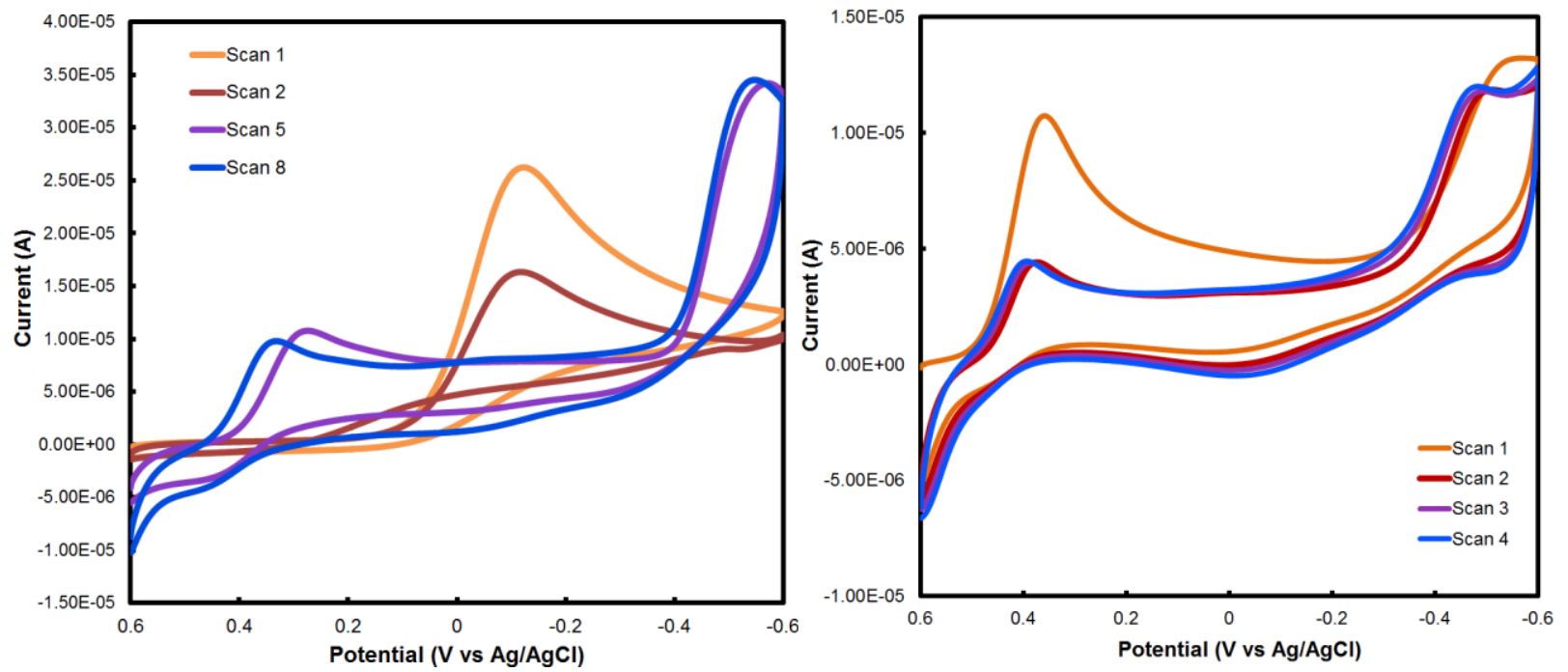

${ }^{1}$ Fig. 2. Multiple cycle CVs $\left(v=0.1 \mathrm{~V} \mathrm{~s}^{-1}\right)$ obtained for 3 at (a) GC electrode (b) Pt electrode in $0.1 \mathrm{M} \mathrm{KCl}$.

The multi-cycle voltammogram obtained with a GC electrode (Figure 2a) shows an initial cathodic peak potential at $-0.122 \mathrm{~V}$ vs $\mathrm{Ag} / \mathrm{AgCl}$ (scan 1). In scan 2 the peak potential shifts only by $5 \mathrm{mV}$ to $-0.117 \mathrm{~V}$; however, there is a significant decrease in the peak current caused by the slow diffusion of $\mathbf{3}$ to the electrode surface. The most dramatic change occurs after scan 2, when $\mathrm{E}_{\mathrm{pc}}$ moves to much more positive values. This change is illustrated by scan 5 , wherein $\mathrm{E}_{\mathrm{pc}}$ has shifted by nearly $400 \mathrm{mV}$ to $0.276 \mathrm{~V}$. Little further change occurs between scan 5 and scan 8 with the current response attaining a near steady state value and $\mathrm{E}_{\mathrm{pc}}$ shifting in the positive direction by only $55 \mathrm{mV}$ to $0.331 \mathrm{~V}$. Importantly, once the $\mathrm{GC}$ electrode is removed from solution and re-polished, $\mathrm{E}_{\mathrm{pc}}$ returns to the initial value seen in scan 1 .

An interesting feature in the multiple-scan CV shown in Figure 2a is eventual appearance of an additional reduction peak at $-0.574 \mathrm{~V}$ in scan 5 , which shifts to $-0.549 \mathrm{~V}$ in scan 8 . Although not confirmed by further experiments, we propose that this peak corresponds to further reduction of the $\mathrm{Pt}(\mathrm{II})$ complex formed in the first

\footnotetext{
${ }^{1}$ The reviewer commented that we assign the two Faradaic responses emerging in scans 5 and 8 in Fig. 2(a) to the reduction of Pt(IV) and $\mathrm{Pt}(\mathrm{II})$, respectively, but that we do not confirm this assignment. The main focus of this paper is to highlight the shape and potential changes of the first Faradaic waves when glassy carbon is used. As the Pt electrode delivers a much more robust and consistent results under identical conditions, Pt electrode is a plausible reference to which the corrective measures we suggest for the glassy carbon electrode can be benchmarked, as the reviewer recognized correctly. Pt electrode was also chosen to be the benchmark for this study since there is no known study where the more accurate dropping mercury electrode is used for these complexes. In this context, however, the actual assignment of these specific potentials to the underlying chemical event is not critical. To do so in a reliable manner, a much more detailed study is required, which would be distracting from the main take-home-message of our paper. We prefer not to comment on this detail to keep the focus on the electrode material dependent responses.
} 
two-electron reaction. ${ }^{2}$ The $\operatorname{Pt}(0)$ produced in this reaction may deposit on the carbon surface of the electrode. It is unclear how the electron transfer kinetics of the $\mathrm{Pt}(\mathrm{IV}) / \mathrm{Pt}(\mathrm{II})$ couple would be affected, but, as we observe faster kinetics at $\mathrm{Pt}$ electrodes, it is plausible that deposition of $\mathrm{Pt}(0)$ on glassy carbon would accelerate the electron transfer rate of the Pt(IV) prodrugs. However, in separate experiments (not shown here) we have observed that GC becomes activated even when voltammetric scans are limited to potentials at which the two-electron reduction to $\operatorname{Pt}(0)$ is not reached. Therefore, the change in response of GC electrodes upon repetitive potential cycling most likely arises from an alteration of the carbon surface and not from the deposition of $\operatorname{Pt}(0)$.

In contrast to the results at $\mathrm{GC}$ electrodes, the $\mathrm{CV}$ in Figure $2 \mathrm{~b}$ clearly demonstrates that pre-trial polishing and multiple scanning have a much smaller influence on the location of the $\mathrm{Pt}(\mathrm{IV})$ peak potential at $\mathrm{Pt}$ electrodes. $\mathrm{E}_{\mathrm{pc}}$ appears at $0.359 \mathrm{~V}$ vs $\mathrm{Ag} / \mathrm{AgCl}$ during the first scan, which is $28 \mathrm{mV}$ more positive even than the final peak potential seen after multiple-scan activation of the glassy carbon electrode (Figure 2a). Moreover, the behavior at platinum is changed only slightly by multiple scanning as indicated by the relatively small positive shift in $\mathrm{E}_{\mathrm{pc}}$ to $0.394 \mathrm{~V}$ in the fourth scan of Figure $2 \mathrm{~b}$. It should be noted that even after activation via multiple scanning to reducing potentials, $\mathrm{E}_{\mathrm{pc}}$ values obtained with $\mathrm{GC}$ never completely achieve the more positive potentials found when employing Pt as the working electrode.

The literature suggests that conventional polishing increases the amount of oxides on a glassy carbon surface. $^{36-38,44}$ Thus, we assume that the unpolished GC electrode following multiple-scan activation should remain activated, even after switching off the potentiostat, replenishing the concentration of $\mathrm{Pt}(\mathrm{IV})$ prodrug adjacent to the electrode surface, and restarting the experiment. The resulting multiple-scan $\mathrm{CV}$ is presented in Figure 3 where the initial $\mathrm{E}_{\mathrm{pc}}$ for reduction of $\mathbf{3}$ is found at a significantly more positive potential of $0.341 \mathrm{~V}$ vs $\mathrm{Ag} / \mathrm{AgCl}$ compared to the initial value of $-0.122 \mathrm{~V}$ shown in Figure 2a. This result demonstrates that the glassy carbon surface remains activated in the absence of an applied potential even when the solution undergoes

\footnotetext{
${ }^{2}$ While the suggestion that new species are formed after the first Faradaic response is possible, we do not feel that it is very likely given the relatively simple redox chemistry of the Pt-species we study here, as well as the time scale of the experiment. More specifically, Pt(II) complexes have been known to catalyze ligand substitution of $\mathrm{Pt}(\mathrm{IV})$ complexes with halide ligands present in the trans position. Among the three molecules we studied, only $3, \mathrm{PtCl}_{4}\left(\mathrm{NH}_{3}\right)_{2}$, has halide ligands in the trans position. But the second, more negative Faradaic response occurs for all three of our Pt(IV) complexes, two of which do not have halide ligands in the trans positions. Even if compound 3 was to undergo ligand exchange, the resulting Pt(IV) complex would be the either 3 or $\left[\mathrm{PtCl}_{3}\left(\mathrm{OH}_{2}\right)\left(\mathrm{NH}_{3}\right)_{2}\right]^{+}$, depending on if the incoming ligand is $\mathrm{Cl}^{-}$or water. Thus, the new species would be reduced either at the same potential or a potential more positive than the original compound $\mathbf{3}$, and not at the far more negative peak potentials seen for the second Faradaic response.
} 
additional stirring or degassing with argon. The phenomenon of GC surface activation is most apparent for $\mathbf{1}$ and 3, where cathodic peak potential differences between Pt and untreated GC are significant. Figures $4 \mathrm{a}$ and $4 \mathrm{~b}$ demonstrate the much improved agreement in $E_{p c}$ values and $E_{p c} v s . \log (v)$ responses achieved by activation of the GC electrode for these two complexes. An additional improvement revealed by the multiple-scan activation procedure is the marked increase in precision of the $E_{p c}$ values obtained at GC for each scan rate. Table 2 enumerates the improvement in standard deviation of the cathodic peak potential determined from three separate trials for compound $\mathbf{3}$.

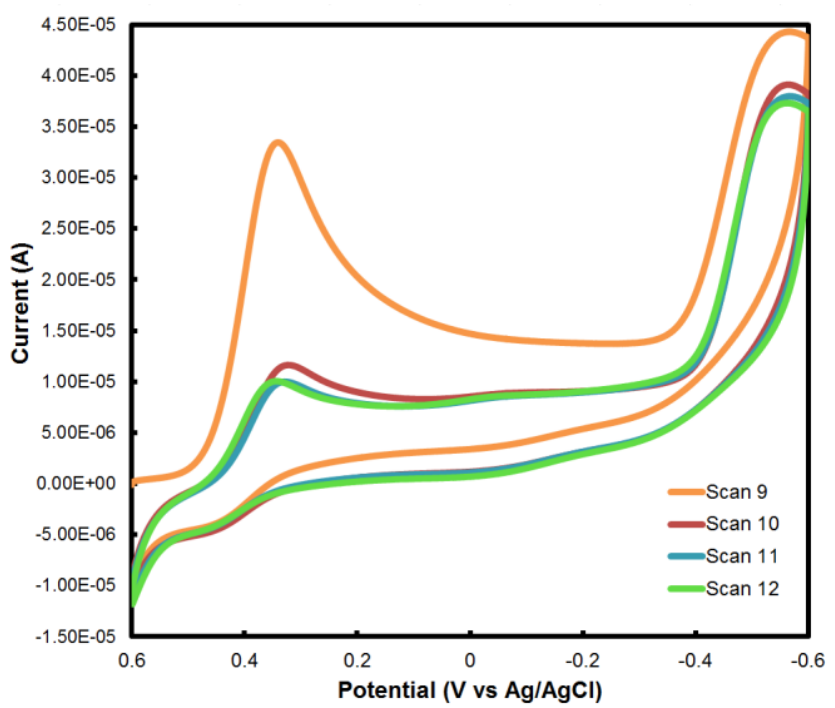

Fig. 3. Multiple CV cycles obtained for $\mathbf{3}$ at an activated GC electrode allowed to remain in solution, but not repolished (see text). 
(a)

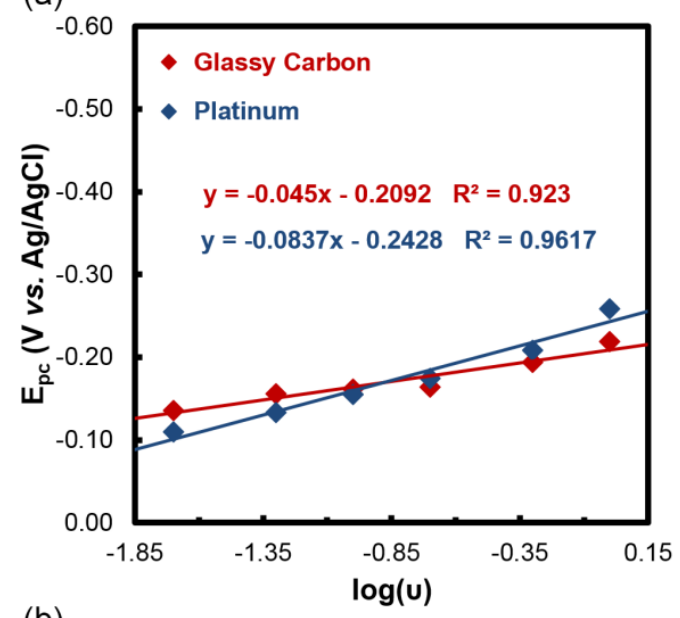

(b)

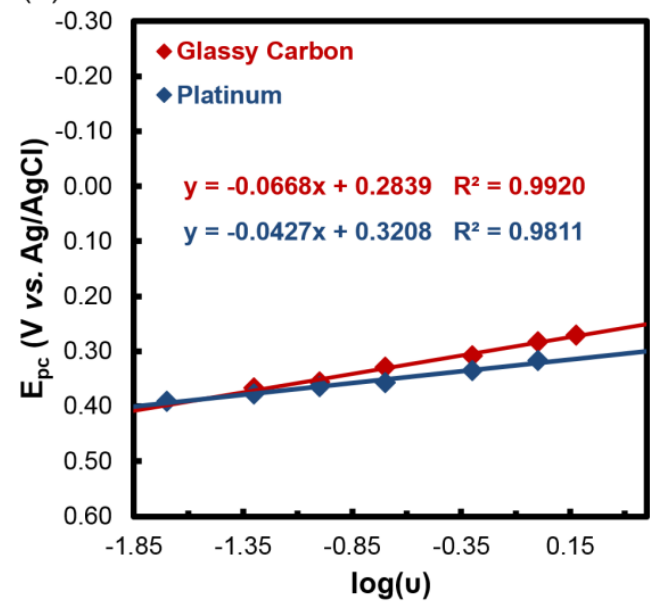

Fig. 4. Plots of $\mathrm{E}_{\mathrm{pc}}(\mathrm{V}$ vs. $\mathrm{Ag} / \mathrm{AgCl})$ as a function of $\log (\mathrm{v})$ illustrating the improved agreement between Pt and activated GC electrode behavior for compounds 1 (a) and $\mathbf{3}$ (b).

\section{Table 2}

Standard deviations $(\mathrm{n}=3)$ for $\mathrm{E}_{\mathrm{pc}}$ values (in $\mathrm{V}$ ) obtained for $\mathbf{3}$ at various scan rates with the use of glassy carbon, activated glassy carbon, and platinum working electrodes.

\begin{tabular}{cccc}
\hline \multirow{2}{*}{ Scan rate $\left(\mathrm{V} \mathrm{s}^{-1}\right)$} & \multicolumn{3}{c}{ standard deviation (in V) } \\
\cline { 2 - 4 } & GC & GC - activated & Pt \\
\hline 0.05 & 0.021 & 0.002 & 0.003 \\
0.1 & 0.012 & 0.003 & 0.005 \\
0.2 & 0.021 & 0.003 & 0.002 \\
0.5 & 0.011 & 0.005 & 0.007 \\
1 & 0.026 & 0.002 & 0.002 \\
1.5 & 0.022 & 0.001 & - \\
\hline
\end{tabular}


A final consideration is the accuracy with which an experimental parameter approximates the reduction potential of a $\mathrm{Pt}(\mathrm{IV})$ prodrug. The fundamental quantity is the thermodynamic potential for addition of one electron to the $\operatorname{Pt}(\mathrm{IV})$ center; i.e., $\mathrm{E}_{1, \mathrm{~s}}{ }^{\circ}$ in Scheme 1. Previously, we determined $\left(\mathrm{E}_{1, \mathrm{~s}}{ }^{\circ}\right)_{\text {expt }}$ by applying Savéant's analysis of irreversible bond-breaking electron transfer reactions to the two-electron reductions of 1-3 using variable scan rate cyclic voltammetry. ${ }^{2}$ As shown in Table 3 these potentials are in very good agreement with values obtained by density functional theory (DFT) calculations, $\left(\mathrm{E}_{1, \mathrm{~s}}{ }^{\circ}\right)_{\text {comput }}$, for the same electrochemical process. However, neither of these approaches is routine, and experimentalists understandably may wish to employ a simpler methodology without sacrificing accuracy. Table 3 shows that voltammetric peak potentials obtained at a scan rate of $0.1 \mathrm{~V} \mathrm{~s}^{-1}$ at both $\mathrm{Pt}$ and activated GC electrodes provide a reasonably accurate approximation of the desired thermodynamic parameter. Unactivated GC electrodes are much less satisfactory in this regard and also are compromised by poor measurement precision. Thus, measurements at Pt or properly activated GC electrodes are recommended for electrochemically assessing the effectiveness of Pt(IV) antitumor prodrugs.

\section{Table 3}

Comparison of potentials for reduction of $\mathrm{Pt}(\mathrm{IV})$ prodrugs $\mathbf{1}-\mathbf{3}$ (V vs. $\mathrm{Ag} / \mathrm{AgCl})$.

\begin{tabular}{cccccc}
\hline Compound & $\mathrm{E}_{\mathrm{pc}, \mathrm{Pt}}{ }^{a}$ & $\mathrm{E}_{\mathrm{pc}, \mathrm{GC}-\text { Activated }}{ }^{a}$ & $\mathrm{E}_{\mathrm{pc}, \mathrm{GC}-\text { Unactivated }}{ }^{a}$ & $\left(\mathrm{E}_{1, \mathrm{~s}}{ }^{\circ}\right)_{\text {expt }}{ }^{b}$ & $\left(\mathrm{E}_{1, \mathrm{~s}}{ }^{\circ}\right)_{\text {comput }^{c}}$ \\
\hline $\mathbf{1}$ & -0.158 & -0.162 & -0.450 & -0.216 & -0.200 \\
$\mathbf{2}$ & 0.083 & 0.092 & 0.091 & 0.100 & 0.199 \\
$\mathbf{3}$ & 0.370 & 0.344 & -0.122 & 0.331 & 0.254 \\
\hline
\end{tabular}

$a=$ This work; Average cathodic peak potential values obtained at $0.1 \mathrm{~V} \mathrm{~s}^{-1} . b=$ Standard reduction potential in Scheme 1 obtained by Savéant analysis of the irreversible two-electron reduction at a Pt electrode; See reference 2. $c=$ Standard reduction potential in Scheme 1 obtained by DFT calculations; See reference 2.

\section{Conclusion}

We have studied the electrochemical reduction of six-coordinate Pt(IV) complexes, which exhibit an irreversible cathodic response in cyclic voltammetry measurements upon insertion of two-electrons and loss of two axial ligands to form square-planar Pt(II) complexes. Heretofore, most investigators have resorted to reporting the cathodic peak potential, $\mathrm{E}_{\mathrm{pc}}$, obtained at a glassy carbon electrode as a substitute for the standard 
redox potential, $\mathrm{E}^{\circ}$, in assessing the efficacy of these antitumor prodrug compounds. However, we recently demonstrated that reduction potentials determined in this manner are seriously in error when compared to consistent values obtained by measurements at platinum electrodes and by quantum chemical calculations. It is shown here that conventionally used glassy carbon electrodes are the source of serious errors and inconsistencies in measuring reduction potentials for Pt(IV) prodrugs. Potentials obtained at Pt electrodes are more positive by ca. 200-600 mV for compounds $\mathbf{1}-\mathbf{3}$ compared to values reported in the current literature where GC is employed. Furthermore, the significant imprecision found among individual GC-derived values reduces confidence in results obtained by this approach, although linear $\mathrm{E}_{\mathrm{pc}} \mathrm{vs} \log (\mathrm{v})$ responses generally are observed.

It is believed that ineffective interaction of $\mathrm{Pt}(\mathrm{IV})$ prodrug complexes with the ill-defined surface of unactivated glassy carbon electrodes results in slow electron transfer due to the need for electrons to tunnel through an ever-present oxide film on the electrode surface. We propose a simple experimental solution that produces more consistent and reproducible data with GC electrodes, whereby the surface is activated through repetitive cycling to negative potentials, which should liberate oxide contaminants and generate a more consistent carbon surface. Large positive shifts in $\mathrm{E}_{\mathrm{pc}}$ are observed on GC as early as the second of a series of multiple scans, and, if an activated electrode is left in solution during stirring or argon purging, the more accurate positive peak potentials are retained. However, a GC electrode repolished in the laboratory ambient reverts to more negative, erroneous $\mathrm{E}_{\mathrm{pc}}$ values. Results obtained with platinum electrodes are largely uninfluenced by polishing or multiple scan treatments. Thus, it is recommended that Pt or appropriately activated GC electrodes be used for redox potential measurements of $\mathrm{Pt}(\mathrm{IV})$ prodrug compounds.

\section{Acknowledgement}

We thank the NSF (0116050, CHE-0645381, CHE-1001589), the Research Corporation (Scialog Award) and the Institute for Basic Science (IBS-R010-D1) for financial support. We also thank Professor Stephen J. Lippard and his group members for generously providing the $\mathrm{Pt}(\mathrm{IV})$-prodrug compounds.

\section{Appendix A. Supplementary material}

Peak potential values, additional multiple-scan CVs. 


\section{AUTHOR INFORMATION}

\section{Corresponding Author}

*E-mail: mbaik2805@kaist.ac.kr

Present Address: Department of Chemistry, Korea Advanced Institute of Science and Technology (KAIST),

Daejeon 339-701, South Korea.

\section{Notes}

The authors declare no competing financial interests. 


\section{References}

(1) Bard, A. J.; Faulkner, L. R. Electrochemical Methods; John Wiley \& Sons, Inc.: New York, 1980.

(2) McCormick, M. C.; Keijzer, K.; Polavarapu, A.; Schultz, F. A.; Baik, M.-H. J. Am. Chem. Soc. 2014, 136, 8992-9000.

(3) Feazell, R. P.; Nakayama-Ratchford, N.; Dai, H.; Lippard, S. J. J. Am. Chem. Soc. 2007, 129, 8438-8439.

(4) Dhar, S.; Lippard, S. J. Proc. Natl. Acad. Sci. U. S. A. 2009106 22199-22204

(5) Giandomenico, C. M.; Abrams, M. J.; Murrer, B. A.; Vollano, J. F.; Rheinheimer, M. I.; Wyer, S. B.; Bossard, G. E.; Higgins, J. D. Inorg. Chem. 1995, 34, 1015-1021.

(6) Hall, M. D.; Hambley, T. W. Coord. Chem. Rev. 2002, 232, 49-67.

(7) Hall, M. D.; Mellor, H. R.; Callaghan, R.; Hambley, T. W. J. Med. Chem. 2007, 50, 3403-3411.

(8) Lemma, K.; Berglund, J.; Farrell, N.; Elding, L. I. J. Biol. Inorg. Chem. 2000, 5, 300-306.

(9) Dhar, S.; Kolishetti, N.; Lippard, S. J.; Farokhzad, O. C. Proc. Natl. Acad. Sci. U. S. A. $20111081850-$

1855

(10) Dhar, S.; Liu, Z.; Thomale, J. r.; Dai, H.; Lippard, S. J. J. Am. Chem. Soc. 2008, 130, 11467-11476.

(11) Wheate, N. J.; Walker, S.; Craig, G. E.; Oun, R. Dalton Trans. 2010, 39, 8113-8127.

(12) Hartwig, J. F.; Lippard, S. J. J. Am. Chem. Soc. 1992, 114, 5646-5654.

(13) Chen, L.; Foo Lee, P.; D. Ranford, J.; J. Vittal, J.; Ying Wong, S. J. Chem. Soc., Dalton Trans. 1999, 1209-1212.

(14) Nakai, T.; Ando, M.; Okamoto, Y.; Ueda, K.; Kojima, N. J. Inorg. Biochem. 2011, 105, 1-5.

(15) Reithofer, M. R.; Bytzek, A. K.; Valiahdi, S. M.; Kowol, C. R.; Groessl, M.; Hartinger, C. G.; Jakupec, M. A.; Galanski, M.; Keppler, B. K. J.Inorg. Biochem. 2011, 105, 46-51.

(16) Platts, J.; Ermondi, G.; Caron, G.; Ravera, M.; Gabano, E.; Gaviglio, L.; Pelosi, G.; Osella, D. J. Biol. Inorg. Chem. 2011, 16, 361-372.

(17) Platts, J. A.; Hibbs, D. E.; Hambley, T. W.; Hall, M. D. J. Med. Chem. 2000, 44, 472-474.

(18) Ellis, L. E., HM; Hambley, TW Aust. J. Chem. 1995, 48, 793-806.

(19) Choi, S.; Filotto, C.; Bisanzo, M.; Delaney, S.; Lagasee, D.; Whitworth, J. L.; Jusko, A.; Li, C.; Wood, N. A.; Willingham, J.; Schwenker, A.; Spaulding, K. Inorg. Chem. 1998, 37, 2500-2504.

(20) Wilson, J. J.; Lippard, S. J. Inorg. Chem. 2011, 50, 3103-3115.

(21) Hall, M. D.; Amjadi, S.; Zhang, M.; Beale, P. J.; Hambley, T. W. J. Inorg. Biochem. 2004, 98, 16141624.

(22) Gramatica, P.; Papa, E.; Luini, M.; Monti, E.; Gariboldi, M.; Ravera, M.; Gabano, E.; Gaviglio, L.; Osella, D. J. Bio. Inorg. Chem. 2010, 15, 1157-1169.

(23) Battle, A. R.; Choi, R.; Hibbs, D. E.; Hambley, T. W. Inorg. Chem. 2006, 45, 6317-6322.

(24) Savéant, J. M. J. Am. Chem. Soc. 1987, 109, 6788-6795.

(25) Andrieux, C. P.; Le Gorande, A.; Savéant, J. M. J. Am. Chem. Soc. 1992, 114, 6892-6904.

(26) Savéant, J. M. J. Am. Chem. Soc. 1992, 114, 10595-10602.

(27) Savéant, J. M. Acc. Chem. Res. 1993, 26, 455-461.

(28) Andrieux, C. P.; Differding, E.; Robert, M.; Savéant, J. M. J. Am. Chem. Soc. 1993, 115, 6592-6599.

(29) Andrieux, C. P.; Robert, M.; Saeva, F. D.; Savéant, J.-M. J. Am. Chem. Soc. 1994, 116, 7864-7871.

(30) Savéant, J. M. J. Phys. Chem. 1994, 98, 3716-3724.

(31) Savéant, J.-M. J. Electroanal. Chem. 2000, 485, 86-88.

(32) Savéant, J.-M. Adv. Phys. Org. Chem. 2000, 117-192.

(33) Costentin, C.; Robert, M.; Savéant, J.-M. Chem. Phys. 2006, 324, 40-56.

(34) Antonello, S.; Musumeci, M.; Wayner, D. D. M.; Maran, F. J. Am. Chem. Soc. 1997, 119, 9541-9549.

(35) Maran, F.; Wayner, D. D. M.; Workentin, M. S. Adv. Phys. Org. Chem. 2001, Volume 36, 85-166.

(36) McCreery, R. L. In Electroanal. Chem.; Bard, A. J., Ed. Dekker, NY, 1991; Vol. 17, p 221-374.

(37) Ranganathan, S.; Kuo, T.-C.; McCreery, R. L. Anal. Chem. 1999, 71, 3574-3580.

(38) Ray Iii, K. G.; McCreery, R. L. J. Electroanal. Chem. 1999, 469, 150-158.

(39) McDermott, M. T.; McDermott, C. A.; McCreery, R. L. Anal. Chem. 1993, 65, 937-944.

(40) Hu, I.-F.; Karweik, D. H.; Kuwana, T. J. Electroanal. Chem. 1985, 188, 59-72.

(41) Rice, R.; Allred, C.; McCreery, R. J. Electroanal. Chem. 1989, 263, 163-169. 
(42) Kneten, K. R.; McCreery, R. L. Anal. Chem. 1992, 64, 2518-2524.

(43) Rice, R. J.; Pontikos, N. M.; McCreery, R. L. J. Am. Chem. Soc. 1990, 112, 4617-4622.

(44) McCreery, R. L. Chem. Rev. 2008, 108, 2646-2687. 

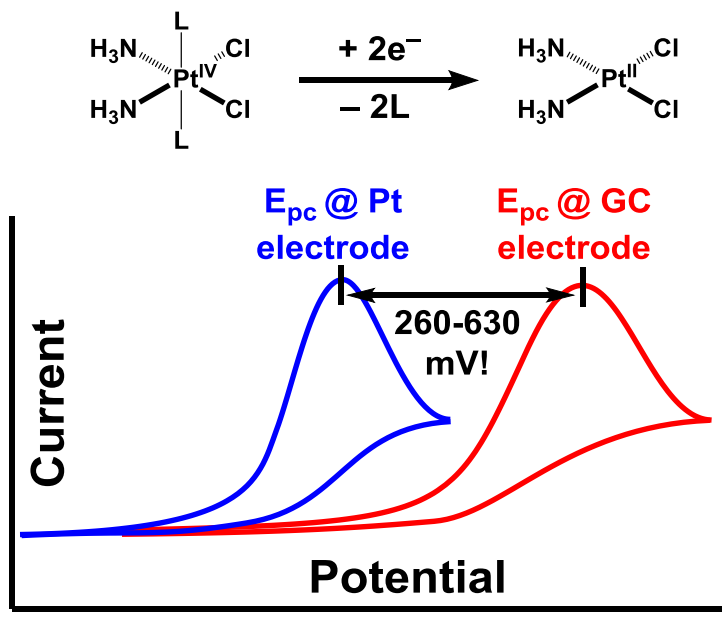

The reduction of $\mathrm{Pt}(\mathrm{IV})$ complexes using glassy carbon (GC) electrode was found to be surprisingly erratic. More reproducible CVs are obtained with platinum metal electrodes and the unreliable and negatively shifted peak potentials are attributed to the oxide layer formed on the GC electrode. 